\title{
Spontaneous splenic rupture related to anticoagulant and antiaggregant treatment
}

\author{
Ebubekir Gündeş ${ }^{1}$, Ulaş Aday², Hüseyin Çiyiltepe², Durmuş Ali Çetin², Emre Bozdağ², Aziz Serkan Senger ${ }^{2}$, \\ Orhan Uzun², Selçuk Gülmez², Kamuran Cumhur Değer², Mustafa Duman² \\ ${ }^{1}$ Gastroenterological Surgery Department, Diyarbakır Gazi Yaşargil Education and Research Hospital, Istanbul, Turkey \\ ${ }^{2}$ Gastroenterological Surgery Department, Kartal Koşuyolu High Speciality and Training Hospital, Istanbul, Turkey
}

Gastroenterology Rev 2019; 14 (2): 152-156

DOI: https://doi.org/10.5114/pg.2019.85900

Key words: spontaneous splenic rupture, anticoagulant treatment.

Address for correspondence: Ebubekir Gündeş MD, Gastroenterological Surgery Department, Diyarbakır Gazi Yaşargil Education and Research Hospital, Denizer cad. No: 22, 34000, Istanbul, Turkey, phone: +90 5058606740, e-mail: ebubekir82@hotmail.com

\begin{abstract}
Introduction: Trauma is the most frequent cause of splenic rupture. In contrast to traumatic rupture of the spleen, spontaneous splenic rupture (SSR) is a rare and life-threatening condition.

Aim: To present the cases of patients with SSR, who had no history of trauma, and who had been receiving anticoagulant and/or antiaggregant treatment while hospitalised for cardiac reasons.

Material and methods: The cases of 6 patients with SSR at Gastroenterological Surgery Department, Kartal Koşuyolu High Speciality and Training Hospital were retrospectively evaluated. The clinicodemographic factors and the diagnostic and therapeutic methods utilised for these patients with SSR while hospitalised were investigated as well.

Results: Five (83.3\%) of the patients were male and 1 (16.6\%) was female. The median age of the patients was 71 (61-73) years. Three of the patients had only been receiving antiaggregant treatment, while 2 had only been receiving anticoagulant treatment; only 1 patient had been receiving both anticoagulant and antiaggregant treatments. The decrease in haematocrit (HCT) levels ascertained on the day of SSR diagnosis and the HCT levels ascertained on the day of hospitalisation were statistically significant. All the patients received a blood transfusion. While 5 (83.33\%) of the 6 patients had splenectomy, 1 (16.66\%) patient received conservative treatment. Mortality was seen in $4(66.6 \%)$ patients.

Conclusions: Spontaneous splenic rupture is a condition that should be taken into consideration in the differential diagnosis of patients hospitalised for cardiac reasons, who are receiving anticoagulant and/or antiaggregant treatment in cases of newly developed abdominal pain and low HCT levels.
\end{abstract}

\section{Introduction}

Trauma is the most frequent cause of splenic rupture. In contrast to traumatic rupture of the spleen, spontaneous splenic rupture (SSR) is a rare and life-threatening condition. There is only limited information about the characteristics of the patients, the incidence, and the aetiology of this condition. The most frequent causes of SSR include infectious diseases, medical procedures, and haematological diseases [1]. The most significant problems seen in this condition are delays in definitive diagnosis and the related destructive results in patients with no history of trauma.

Spontaneous splenic rupture related to anticoagulant and/or antiaggregant use is very rare, and litera- ture on the subject only discusses it in the form of case reports $[1,2]$.

\section{Aim}

The objective of this study is to review the cases of patients with SSR who are receiving anticoagulant and/ or antiaggregant treatment and who have no previous history of trauma; this study also seeks to identify the mode of treatment utilised for this very rare condition.

\section{Material and methods}

\section{Study design}

The cases of 6 patients with SSR between January 2013 and December 2016 at Gastroenterological Surgery Department, Kartal Koşuyolu High Speciality and 
Training Hospital were retrospectively evaluated. It was not necessary to obtain informed consent from the patients because of the retrospective nature of the study.

\section{Study population}

Patients who contracted SSR at the time of hospitalisation at the cardiology and cardiovascular surgery clinics, and who received conservative treatment or surgical procedures following our evaluation, were included in the study. Patients with a history of trauma and/or a history of laparotomy at the time of hospitalisation were excluded from the study.

\section{Data}

Anamnesis, age, sex, accompanying diseases, and reasons for antiaggregant and/or anticoagulant prescriptions were recorded for all 6 patients following the review of their archive files and the hospital's electronic archive system. The results of the following radiological diagnostic methods at the time of hospitalisation and diagnosis were also recorded: haematocrit ( $\mathrm{HCT})$, activated partial thromboplastin time (APTT), international normalised ratio (INR), and platelet (PLT) values.

Post-diagnostic medical and surgical modes of treatment for haematoma, the number of blood and blood product replacements, the rate of mortality, and the period of hospitalisation were investigated. Post-operative mortality cases during the first 30-day follow-up period were evaluated as operative mortality, while surgical complications that developed during this period were considered to be morbidity.

All the data were saved in Excel tables without any identifying information to protect the patients' confidentiality and to prevent their names from being revealed.

\section{Statistical analysis}

Statistical Package for the Social Sciences (SPSS 21 Inc., Chicago, IL, USA) computer software was used for the bio-statistical analyses. When the data were presented as mean values their standard deviation values were also stated, and when the data were presented as median values their minimum-maximum values were also stated. Differences among the groups with normal distribution were compared using the $t$-test. The level of significance was set at the $p<0.05$ level.

\section{Results}

\section{Baseline patient characteristics}

Six patients with SSR were treated at our clinic during the time period of the study. Five $(83.3 \%)$ of the 6 patients were male and 1 (16.6\%) was female. Their mean age was $69.17 \pm 4.79$ years. Each patient had at least one accompanying comorbidity. Three of the $6 \mathrm{pa}-$ tients had been receiving antiaggregant treatment only, while 2 had been receiving anticoagulant treatment only; just 1 of the 6 patients had been receiving both anticoagulant and antiaggregant treatments. The indications for anticoagulant and antiaggregant treatment of the patients were as follows: 2 patients received treatment for a coronary angiography-stent procedure, 1 patient received treatment following atrial fibrillation (AF), 1 patient received treatment following coronary arterial bypass graft (CABG), 1 patient received treatment following endovascular aneurysm repair (EVAR), and 1 patient received treatment for a peripheral arterial embolectomy procedure. The demographic features of the patients are presented in Table I.

\section{Diagnosis}

The physical examination revealed that 5 of the patients had extensive abdominal sensitivity and distension. The abdominal examination of the patient that had not undergone surgery showed no distension, but there was sensitivity in the left quadrants. Three of the cases initially had undergone abdominal ultrasonography (USG), and all the patients, including those three,

Table I. Demographic characteristics of the patients

\begin{tabular}{|c|c|c|c|c|c|}
\hline Patient & Age [years] & Gender & Medication related & Indications treatment & Comorbidities \\
\hline 1 & 61 & M & Heparin & Peripheral arterial disease - embolectomy & CRF \\
\hline 2 & 66 & $\mathrm{~F}$ & Warfarin + LMWH & Atrial fibrillation & CHF-CRF \\
\hline 3 & 73 & M & Clopidogrel & NSTMI-coronary angiography stent placement & HT- DM \\
\hline 4 & 72 & M & $A S A+L M W H$ & $M I-C A B G$ & HT \\
\hline 5 & 70 & M & ASA & Abdominal aortic aneurysm - EVAR & CRF \\
\hline 6 & 73 & M & Clopidogrel & NSTMI - coronary angiography stent placement & HT \\
\hline
\end{tabular}

AS - acetylsalicylic acid, LMWH - low-molecular-weight heparin, NSTMI - non-ST-segment elevation myocardial infarction, MI - myocardial infarction, $C A B G$ - coronary artery bypass graft, EVAR - endovascular aneurysm repair, CRF-chronic renal failure, CHF-congestive heart failure, HT - hypertension, $D M$ - diabetes mellitus. 
had undergone computerised tomography (CT) (Figures $1 \mathrm{~A}, \mathrm{~B}, 2 \mathrm{~A}, \mathrm{~B})$. Patients with a mean HCT level of 35.17 $\pm 2.3 \%$ at the time of hospitalisation also had a mean HCT level of $21.56 \pm 2.29 \%$ at the time of SSR diagnosis, and this decrease was statistically significant $(p<0.05)$. The median APTT level of the patients at the time of diagnosis was $42.75 \mathrm{~s}$ (28-89.6), their median INR level was 1.29 (1.1-2.19), and their median PLT value was $208 \times 10^{3} / \mu \mathrm{l}(105-244)$.

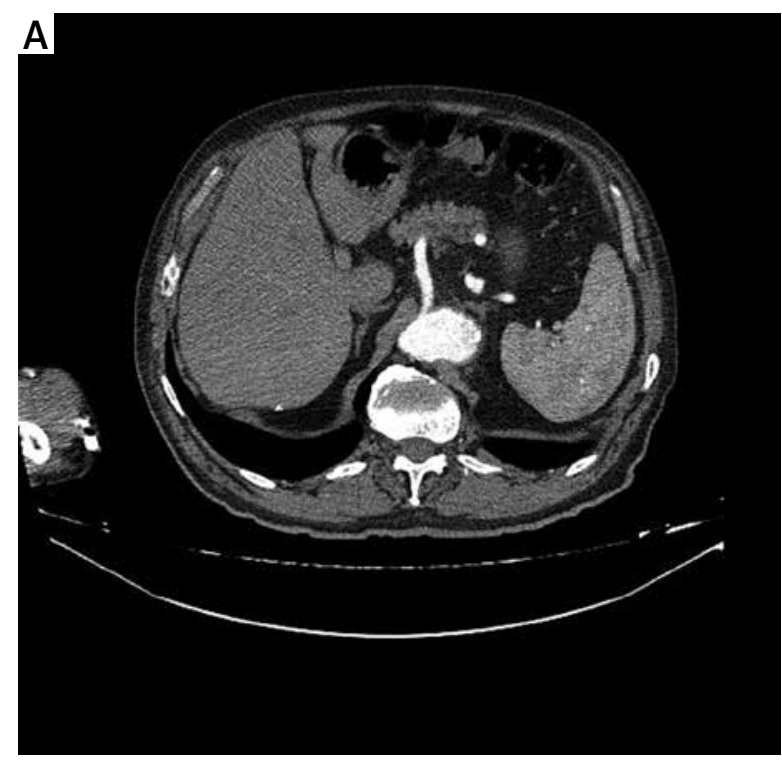

\section{Outcomes}

All the patients received red blood cell packs, and the mean amount of transfusion was $10.67 \pm 6.18 \mathrm{U}$. However, 1 of the patients had a history of CABG, while another had a history of EVAR. While $5(83.33 \%)$ of the cases had splenectomy, 1 (16.66\%) received conservative treatment. The preoperative status, diagnoses, and treatment modes of the patients are summarised in Table II.

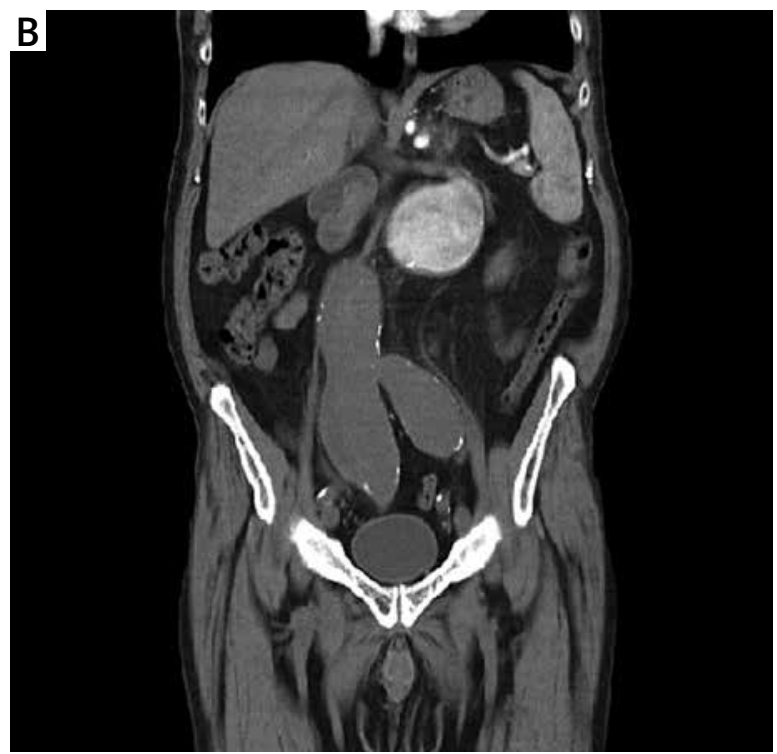

Figure $1 \mathrm{~A}, \mathrm{~B}$. Axial and coronal computerised tomography image of the abdominal aortic aneurism, which was detected at the patient's initial hospitalisation, and the normal spleen of case number 5
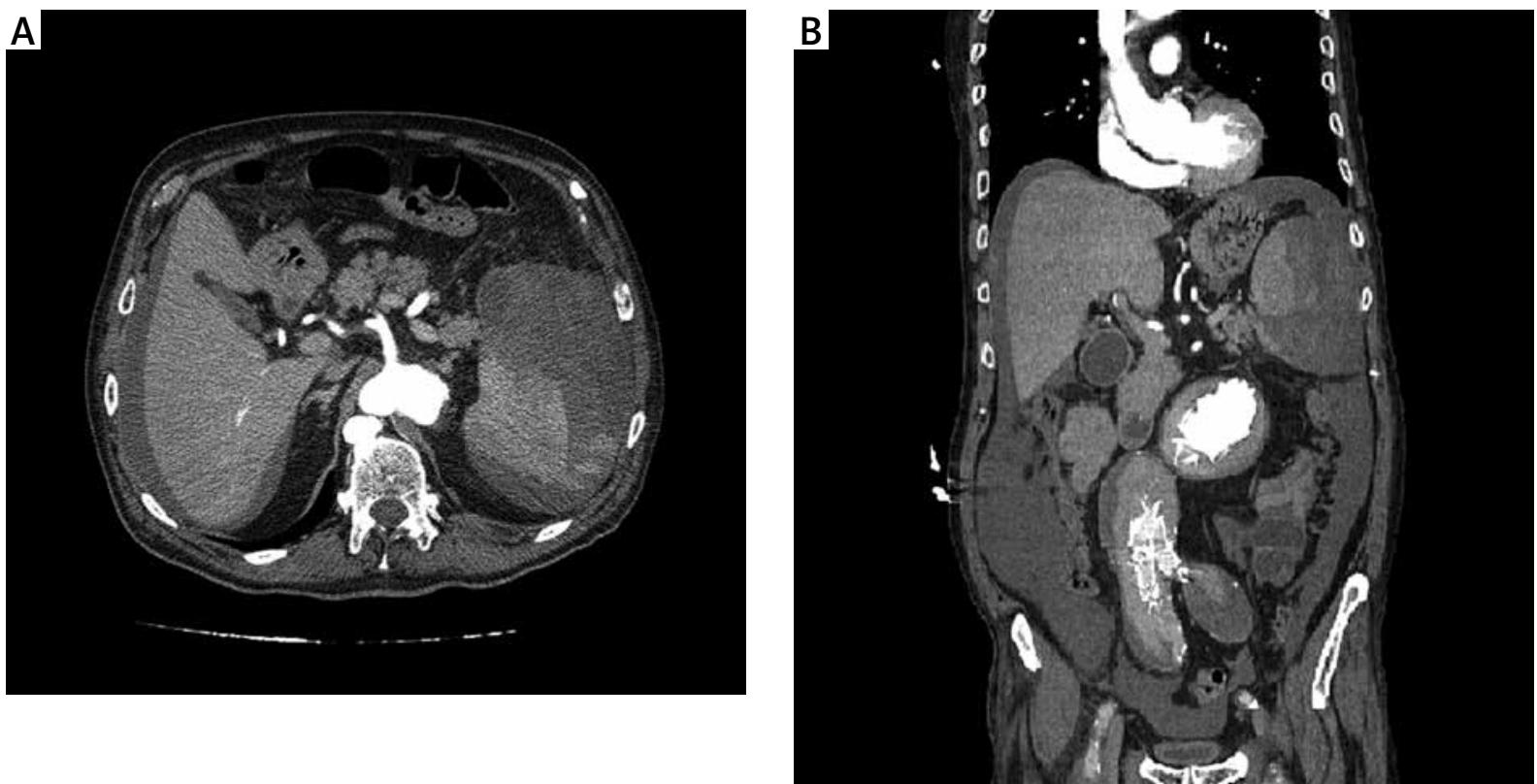

Figure 2 A, B. Axial and coronal computerised tomography image of the splenic rupture and the abdominal aortic stent of case number 5 following endovascular aneurysm repair and aspirin treatment 
Table II. Diagnosis and treatment

\begin{tabular}{|c|c|c|c|c|c|c|c|c|}
\hline Patient & $\begin{array}{c}\text { Preoperative } \\
\text { disposition }\end{array}$ & $\begin{array}{c}\text { At the time of } \\
\text { diagnosis HCT (\%) }\end{array}$ & aPTT [s] & INR & $\begin{array}{c}\text { PLT } \\
{\left[\times 10^{3} / \mu \mathrm{l}\right]}\end{array}$ & $\begin{array}{l}\text { Diagnostic } \\
\text { method }\end{array}$ & Treatment & Histopathology \\
\hline 1 & Awake, in ICU & 21 & 89.6 & 2 & 210 & CT & Splenectomy & Nonspecific \\
\hline 2 & Awake, in ICU & 20 & 52.8 & 2.19 & 244 & USG, CT & Splenectomy & Nonspecific \\
\hline 3 & Awake, in ICU & 22 & 67.1 & 1.31 & 206 & CT & Splenectomy & Nonspecific \\
\hline 4 & $\begin{array}{l}\text { Intubated, } \\
\text { in ICU }\end{array}$ & 20.4 & 31 & 1.11 & 211 & USG, CT & Splenectomy & Nonspecific \\
\hline 5 & $\begin{array}{l}\text { Intubated, } \\
\text { in ICU }\end{array}$ & 20 & 32.7 & 1.28 & 105 & USG, CT & Splenectomy & Nonspecific \\
\hline 6 & $\begin{array}{l}\text { Awake, } \\
\text { on patient } \\
\text { floor }\end{array}$ & 26 & 28 & 1.13 & 178 & CT & Conservative & Nonspecific \\
\hline
\end{tabular}

ICU - intensive care unit, HCT - haematocrit, aPTT - activated partial thromboplastin time, INR - international normalised ratio, PLT-platelet, CT - computed tomography, USG - ultrasonography.

Table III. Postoperative complications and follow-up

\begin{tabular}{|c|c|c|c|c|c|c|c|}
\hline Patient & $\begin{array}{l}\text { The time of } \\
\text { diagnosis after } \\
\text { hospitalisation } \\
\text { [days] }\end{array}$ & $\begin{array}{l}\text { Length of stay } \\
\text { in ICU [days] }\end{array}$ & $\begin{array}{c}\text { Length of stay } \\
\text { in hospital } \\
\text { [days] }\end{array}$ & $\begin{array}{c}\text { Number } \\
\text { of RBCP } \\
\text { transfused [U] }\end{array}$ & $\begin{array}{c}\text { Complications } \\
\text { (30-day) }\end{array}$ & $\begin{array}{l}\text { Mortality } \\
\text { (30-day) }\end{array}$ & Late outcome \\
\hline 1 & 2 & 8 & 9 & 9 & MOF & Yes & Operative death \\
\hline 2 & 8 & 7 & 14 & 20 & ARF - sepsis & Yes & Operative death \\
\hline 3 & 3 & 29 & 30 & 15 & ARF - sepsis & Yes & Operative death \\
\hline 4 & 8 & 4 & 10 & 10 & MOF & Yes & Operative death \\
\hline 5 & 15 & 5 & 25 & 8 & $\begin{array}{c}\text { Redo } \\
\text { laparotomy } \\
\text { (bleeding) }\end{array}$ & No & $\begin{array}{l}18 \text { months } \\
\text { in life }\end{array}$ \\
\hline 6 & 2 & 1 & 10 & 2 & No & No & 6 months in life \\
\hline
\end{tabular}

$R B C P$ - red blood cell packs, ARF-acute renal failure, MOF-multiorgan failure.

The mean duration of hospitalisation of the patients was $16.3 \pm 8.95$ days, while the mean time of diagnosis for SSR was $6.33 \pm 5.08$ days of hospitalisation.

Laparotomy had to be redone for 1 patient due to bleeding after surgery. Mortality was seen in 4 (66.6\%) patients who underwent surgery. The patients' follow-ups are summarised in Table III.

\section{Discussion}

Atraumatic or SSR was first described by Orloff and Peskin in 1958, and four diagnostic criteria were established: the absence of history of trauma in the patient, the absence of perisplenic adhesions that could support previous traumas, the absence of diseases affecting the spleen, and a natural spleen, as determined using both microscopic and macroscopic analysis methods [3]. In all our patients, SSR developed during hospitalisation for other reasons, and they had no history of trauma.

Atraumatic splenic rupture can appear as a complication of neoplastic, infectious, inflammatory, and genetic disorders. Various drugs and modes of treatment have also been associated with atraumatic splenic ruptures. A literature review by Aubrey-Bassler and Sowers in 2012 [4] reported on 47 cases with SSR related to drug use; of those cases, 22 of the patients were on anticoagulants, 13 were on thrombolytics, 10 were on recombinant granulocyte colony stimulating factor (G-CSF), and two were on anti-platelet agents. Both of the patients who were on anti-platelets were using ticlopidine. In their 2014 study of 12 cases with SSR, Kocael et al. [5] found anticoagulant use in three cases and acetyl salicylic acid (ASA) use in 1 case. In our study, 2 of the 3 patients who had been on anti-platelets were using clopidogrel, while one was using ASA.

The SSR shows a clinical progression similar to what is observed in patients with traumatic splenic rupture. Abdominal pain in the upper left quadrant, nausea, vomiting, dizziness, and syncope symptoms can be seen before shock symptoms $[4,5]$. In general, our patients had abdominal pain. Abdominal examination also 
demonstrated that most of the patients had extensive sensitivity and distension symptoms.

Abdominal CT is the imaging method most frequently used for diagnosis [5]. However, some studies suggest that USG should be utilised [6]. Although 3 of the 6 patients in our study had undergone USG, all the patients had CT scans in order to exclude other intra-abdominal pathologies and to obtain a definitive diagnosis.

In their 845-case systematic review, Ranzulli et al. [7] stated that $84.1 \%$ of the cases had splenectomy, $1.2 \%$ had organ-protective surgery, and $14.7 \%$ were treated by conservative measures. Ranzulli et al. [7] also found the SSR-related mortality rate to be $12.2 \%$. In our study, the mortality rate was found to be much higher than in that study. We believe that this difference is due to several factors. First, our patients contracted SSR at the time of hospitalisation for cardiac reasons. Second, our SSR patients had accompanying diseases. Third, our patients were elderly. Fourth, the use of anticoagulant and antiaggregant treatments increased the amount and severity of bleeding.

\section{Conclusions}

Consequently, SSR is a condition that should be taken into consideration in differential diagnosis because it could lead to serious mortality in cases with newly developed abdominal pain and low HCT levels in patients who are hospitalised for cardiac reasons and are taking anticoagulant and/or antiaggregant medication.

\section{Conflict of interest}

The authors declare no conflict of interest.

\section{References}

1. de Kubber MM, Kroft LJ, de Groot B. Non-traumatic splenic rupture in a patient on oral anticoagulation. Int J Emerg Med 2013; 6: 16.

2. Loizon P, Nahon P, Founti H, et al. Spontaneous rupture of the spleen under ticlopidine. Apropos of two cases. J Chir 1994; 131: 371-4.

3. Orloff MJ, Peskin GW. Spontaneous rupture of the normal spleen; a surgical enigma. Int Abstr Surg 1958; 106: 1-11.

4. Aubrey-Bassler FK, Sowers N. 613 cases of splenic rupture without risk factors or previously diagnosed disease: a systematic review. BMC Emerg Med 2012; 12: 11.

5. Kocael PC, Simsek O, Bilgin IA, et al. Characteristics of patients with spontaneous splenic rupture. Int Surg 2014; 99: 714-8.

6. Gedik E, Girgin S, Aldemir M, et al. Non-traumatic splenic rupture: report of seven cases and review of the literature. World J Gastroenterol 2008; 14: 6711-6.

7. Renzulli P, Hostettler A, Schoepfer AM, et al. Systematic review of atraumatic splenic rupture. Br J Surg 2009; 96: 1114-21.
Received: 10.09.2017

Accepted: 6.12.2017 